Leal, U.N.M.; Antunes, F.; Nogueira, F.A.; Schafer, M.M.; Oliveira, MTC. Análise preliminar da infraestrutura e do uso público da Estação Ecológica de Mogi-Guaçu (SP). Anais do VIII Congresso Nacional de Ecoturismo e do IV Encontro Interdisciplinar de Ecoturismo em Unidades de Conservação. Revista Brasileira de Ecoturismo, São Paulo, v.4, n.4, 2011, p. 536.

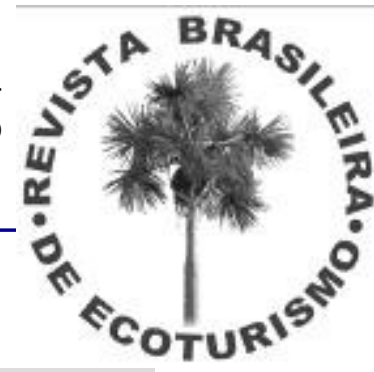

\title{
ANÁLISE PRELIMINAR DA INFRA-ESTRUTURA E DO USO PÚBLICO DA ESTAÇÃO ECOLÓGICA DE MOGI-GUAÇU (SP)
}

\section{Ulisses Nascimento Mazzucato Leal, Fagner Antunes, Flávio Augusto Nogueira, Márcio Marques Schafer, Marcelo Teixeira Cesar de Oliveira}

Centro Universitário São Camilo,

\begin{abstract}
E-mails: leal.ulisses@gmail.com, fagnerantunes@terra.com.br,fan_nogueira@hotmail.com, marcioschafer@msn.com, marcelotco@ipatiua.com.br
\end{abstract}

A Estação Ecológica (E.E.) de Mogi-Guaçu, situada entre as coordenadas $22^{\circ} 30^{\prime} \mathrm{S}$ e $47^{\circ} 1^{\prime} \mathrm{O}$, fica dentro do município de Conchal, São Paulo. Foi inicialmente uma Estação Experimental e se tornou uma Unidade de Conservação pelo Decreto Estadual 22.336 de 1984. Tem o objetivo de proteger as formações vegetais de Cerrado e Mata Atlântica que ocorrem na região. Possui uma biodiversidade representativa destes ecossistemas, com espécies da fauna e flora endêmicas, além de ameaçadas de extinção como o Lobo Guará (Chrysocyon brachyurus). A área total de 980,71 ha, apresenta relevo composto de colinas amplas e planícies aluviais, com altitudes entre 560 e 700 metros. Está inserida na bacia hidrográfica do rio Mogi-Guaçu, tendo o rio Pardo como seu principal afluente. O objetivo deste trabalho foi realizar o levantamento preliminar da infraestrutura para uso público, com a finalidade de analisar este aspecto e verificar suas condições e adequação. Foi realizada pesquisa bibliográfica e webgráfica. O levantamento local foi feito durante o segundo semestre de 2009 através de registros fotográficos, observação, anotações de campo além de colher o relato do técnico em pesquisa responsável pelo local. A E. E. apresenta fácil acesso ao visitante com entrada gratuita mas controlada por guarita na entrada, apesar de contar com apenas seis seguranças para cobrir a área total. A presença de um pesqueiro na margem oposta do rio Mogi-Guaçu permite a entrada na área sem controle da vigilância.Constatou-se que a equipe administrativa é insuficiente, composta por apenas um funcionário, devido a falta de recursos do Estado. Numa pequena instalação funcionam o centro de visitantes -com o mapa da E. E. e alguns cartazes para identificação de aves-, a área administrativa e o alojamento para pesquisadores. Notou-se a ausência de equipamentos de lazer como playground. Os sanitários são encontrados somente nesta área bem como as lixeiras que são ausentes ao longo das trilhas abertas à visitação. Em apenas uma das trilhas foram observadas placas indicativas, com informações como nome da trilha, trajeto e fauna e flora que podem ser observadas, porém, estavam muito degradadas necessitando de substituição. Existem equipamentos tais como TV e Home Theater, mas sem uso devido a falta de local para abrigar atividades de educação ambiental com escolas e visitantes. No geral, a Estação atende somente alunos de escolas da região, contando com um projeto de educação ambiental da SMA-SP. Porém, durante a visita, não houve oportunidade de acompanhar o trabalho de monitores pois ainda estavam em processo de contratação. Além disso, há um viveiro com mudas de espécies nativas para replantio, que pode ser visitado e ser utilizado com os estudantes nos programas de E.A. O Plano de Manejo, tinha previsão de ser implantado no fim de 2009 mas seu lançamento foi adiado. A E.E. portanto não apresenta infra-estrutura adequada para receber uma grande quantidade de visitantes e mesmo recebendo pequenos grupos ainda carece de pessoal, instalações e equipamentos adequados, bem como materiais informativos que destaquem a grande importância ecológica da área, informação importante de ser disseminada pelos programas de visitação.

Palavras-Chave: Us Públicoo; Estação Ecológica e Mogi-Guaçu; Infraestrutura. 